\title{
MHD Slip Flow past a Shrinking Sheet
}

\author{
Santosh Chaudhary, Pradeep Kumar \\ Department of Mathematics, Malaviya National Institute of Technology, Jaipur, Rajasthan, India \\ Email: d11.santosh@yahoo.com,pradeep17matrix@gmail.com
}

Received November 28, 2012; revised January 18, 2013; accepted January 26, 2013

\begin{abstract}
An analysis is made for the steady two-dimensional laminar boundary layer flow of a viscous, incompressible, electrically conducting fluid near a stagnation point past a shrinking sheet with slip in the presence of a magnetic field. The governing boundary layer equations are transformed to ordinary differential equations by taking suitable similarity variables and solved numerically by Shooting method. The effects of the various parameters such as velocity ratio parameter, slip parameter, Prandtl number, Eckert number and magnetic parameter for velocity and temperature distributions have been discussed in detail through graphical representation.
\end{abstract}

Keywords: MHD; Boundary Layer; Slip Flow; Shrinking Sheet

\section{Introduction}

The viscous flow and heat transfer in the boundary layer region due to a stretching sheet has wide theoretical and technical applications in manufacturing process and in industries such as extraction of polymer sheet, paper production, wire drawing, glass-fiber production, the cooling and drying of paper and textiles. The study of heat transfer and flow field is necessary for determining the quality of the final products of such process. Crane [1] was first who considered steady boundary layer flow of a viscous incompressible fluid over a linearly stretching plate and gave an exact similarity solution in closed analytical form. The effects of heat and mass transfer and magnetic field under various physical conditions have been investigated by several authors such as Chen and Char [2], Chiam [3], Andersson [4], Ariel et al. [5], Jat and Chaudhary [6,7], Wang [8], Fang et al. [9], Nadeem et al. [10], Bhattacharyya and Layek [11] and recently Bhattacharyya et al. [12] studied the slip effects on boundary layer stagnation-point flow and heat transfer towards a shrinking sheet.

Based on the above mentioned investigations and applications, this paper is concerned with a steady, two dimensional stagnation flow of an electrically conducting fluid past a shrinking sheet in the presence of a magnetic field. The results of velocity and temperature distributions for different parameters such as the velocity ratio parameter, the slip parameter, the Prandtl number, the Eckert number and the magnetic parameter were obtained.

\section{Formulation of the Problem}

Consider the steady two-dimensional laminar flow of a viscous incompressible electrically conducting fluid towards a linearly shrinking sheet such that the sheet is shrinked in its own plane with velocity proportional to the distance from the stagnation point in the presence of an externally applied normal magnetic field of constant strength $H_{0}$. The shrinking surface has a linear velocity $u_{w}(x)$ and uniform temperature $T_{w}$, while the velocity of the flow external to the boundary layer is $u_{e}(x)$ and temperature $T_{\infty}$ as shown in Figure 1. Therefore, under the usual boundary layer approximations, the governing equations of motion are:

$$
\begin{aligned}
& \frac{\partial u}{\partial x}+\frac{\partial v}{\partial y}=0 \\
& u \frac{\partial u}{\partial x}+v \frac{\partial u}{\partial y} \\
& =u_{e} \frac{\mathrm{d} u_{e}}{\mathrm{~d} x}+v \frac{\partial^{2} u}{\partial y^{2}}-\frac{\sigma_{e} \mu_{e}^{2} H_{0}^{2} u}{\rho} \\
& \rho C_{p}\left(u \frac{\partial T}{\partial x}+v \frac{\partial T}{\partial y}\right) \\
& =\kappa \frac{\partial^{2} T}{\partial y^{2}}+\mu\left(\frac{\partial u}{\partial y}\right)^{2}+\sigma_{e} \mu_{e}^{2} H_{0}^{2} u^{2}
\end{aligned}
$$

where $v$ is the coefficient of kinematic viscosity, $\sigma_{e}$ the electrical conductivity, $\mu_{e}$ the magnetic permeability, $\rho$ the density, $C_{p}$ the specific heat at constant pressure, $\kappa$ the thermal conductivity and $\mu$ the coefficient of viscosity. The other symbols have their usual 


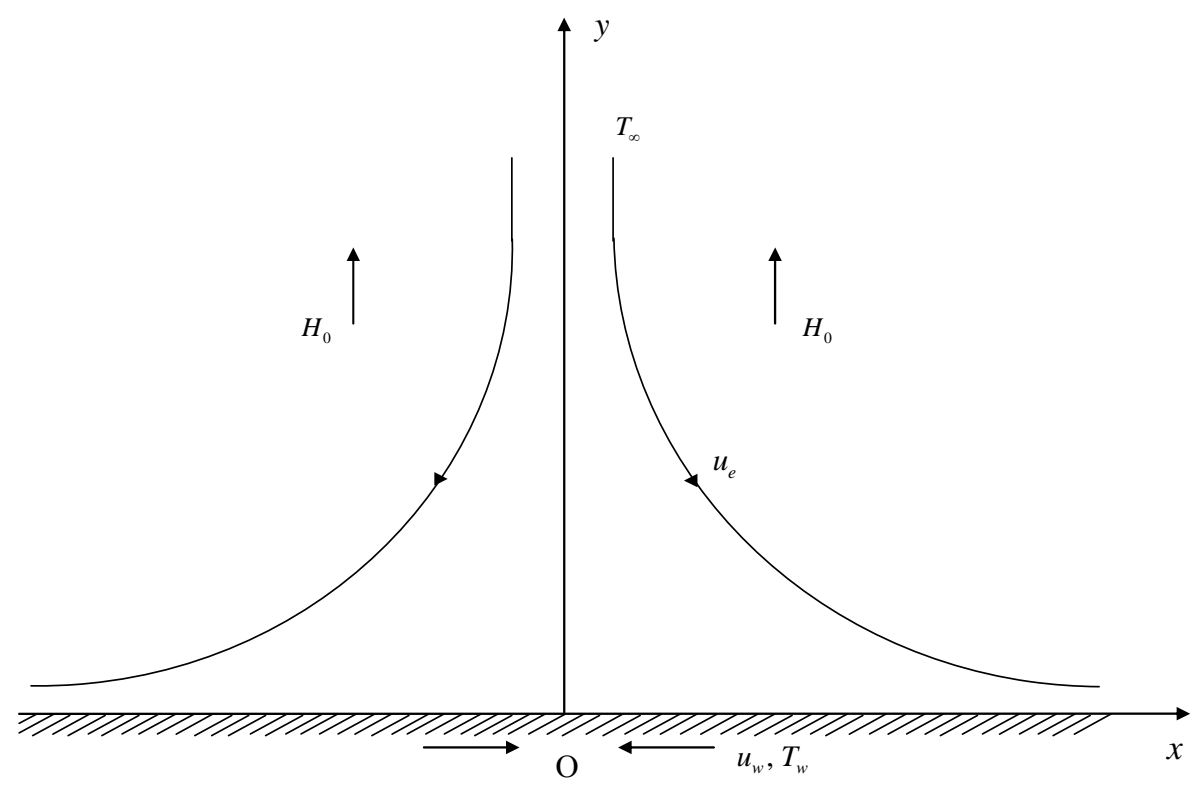

Figure 1. Physical model of two-dimensional stagnation point flow past a shrinking sheet.

meanings.

The boundary conditions are:

$$
\begin{aligned}
& y=0: u=u_{w}=c x+L\left(\frac{\partial u}{\partial y}\right), v=0 ; T=T_{w} \\
& y=\infty: u=u_{e}(x)=a x ; T=T_{\infty}
\end{aligned}
$$

where $c$ is a proportionality constant of the velocity of shrinking sheet, $L$ is a slip length and $a$ is a constant proportional to the free stream velocity for away from the sheet.

\section{Analysis of the Velocity and the Thermal Boundary Layers}

The continuity Equation (1) is identically satisfied by stream function $\psi(x, y)$, defined as

$$
u=\frac{\partial \psi}{\partial y}, \quad v=-\frac{\partial \psi}{\partial x}
$$

For the solution of the momentum and the energy Equations (2) and (3), the following dimensionless variables are defined:

$$
\begin{aligned}
& \psi(x, y)=\sqrt{a v} x f(\eta) \\
& \eta=\sqrt{\frac{a}{v}} y \\
& \theta(\eta)=\frac{T-T_{\infty}}{T_{w}-T_{\infty}}
\end{aligned}
$$

Equations (5) to (8), transform Equations (2) and (3) into

$$
f^{\prime \prime \prime}+f f^{\prime \prime}-f^{\prime 2}-\operatorname{Re}_{m}^{2} f^{\prime}+1=0
$$

$$
\theta^{\prime \prime}+\operatorname{Pr} f \theta^{\prime}+\operatorname{Pr} E c f^{\prime \prime 2}+\operatorname{Pr} E c \operatorname{Re}_{m}^{2} f^{\prime 2}=0
$$

where a prime (') denotes differentiation with respect to $\eta, \operatorname{Re}_{m}=\mu_{e} H_{0} \sqrt{\frac{\sigma_{e}}{\rho a}}$ is the Magnetic parameter, $\operatorname{Pr}=\frac{\mu C_{p}}{\kappa}$ is the Prandtl number and $E c=\frac{u_{e}^{2}}{C_{p}\left(T_{w}-T_{\infty}\right)}$ is the Eckert number.

The corresponding boundary conditions are:

$$
\begin{aligned}
& \eta=0: f=0, f^{\prime}=\frac{c}{a}+\delta f^{\prime \prime} ; \theta=1 \\
& \eta=\infty: f^{\prime}=1 ; \theta=0
\end{aligned}
$$

where $\frac{c}{a}$ is the velocity ratio parameter and $\delta=L\left(\frac{a}{v}\right)^{\frac{1}{2}}$ is the slip parameter.

For numerical solution of the Equations (9) and (10), we apply the following power series in a small magnetic parameter $\mathrm{Re}_{m}^{2}$ as:

$$
\begin{aligned}
& f(\eta)=\sum_{i=0}^{\infty}\left(\operatorname{Re}_{m}^{2}\right)^{i} f_{i}(\eta) \\
& \theta(\eta)=\sum_{j=0}^{\infty}\left(\operatorname{Re}_{m}^{2}\right)^{j} \theta_{j}(\eta)
\end{aligned}
$$

Substituting Equations (12) and (13) and its derivatives in Equations (9) and (10) and then equating the coefficients of like powers of $\operatorname{Re}_{m}^{2}$, we get the following set of equations:

$$
f_{0}^{\prime \prime \prime}+f_{0} f_{0}^{\prime \prime}-f_{0}^{\prime 2}+1=0
$$




$$
\begin{gathered}
\theta_{0}^{\prime \prime}+\operatorname{Pr} f_{0} \theta_{0}^{\prime}=-\operatorname{Pr} E c f_{0}^{\prime \prime 2} \\
f_{1}^{\prime \prime \prime}+f_{0} f_{1}^{\prime \prime}-2 f_{0}^{\prime} f_{1}^{\prime}+f_{0}^{\prime \prime} f_{1}=f_{0}^{\prime} \\
\theta_{1}^{\prime \prime}+\operatorname{Pr} f_{0} \theta_{1}^{\prime} \\
=-\operatorname{Pr} f_{1} \theta_{0}^{\prime}-\operatorname{Pr} E c\left(2 f_{0}^{\prime \prime} f_{1}^{\prime \prime}+f_{0}^{\prime 2}\right) \\
f_{2}^{\prime \prime \prime}+f_{0} f_{2}^{\prime \prime}-2 f_{0}^{\prime} f_{2}^{\prime}+f_{0}^{\prime \prime} f_{2} \\
=-f_{1} f_{1}^{\prime \prime}+\left(f_{1}^{\prime}+1\right) f_{1}^{\prime} \\
\theta_{2}^{\prime \prime}+\operatorname{Pr} f_{0} \theta_{2}^{\prime}=-\operatorname{Pr}\left(f_{1} \theta_{1}^{\prime}+f_{2} \theta_{0}^{\prime}\right) \\
\quad-\operatorname{Pr} E c\left(2 f_{0}^{\prime \prime} f_{2}^{\prime \prime}+f_{1}^{\prime \prime 2}+2 f_{0}^{\prime} f_{1}^{\prime}\right)
\end{gathered}
$$

with the boundary conditions:

$$
\begin{aligned}
& \eta=0: f_{i}=0, f_{0}^{\prime}=\frac{c}{a}+\delta f_{0}^{\prime \prime}, f_{j}^{\prime}=\delta f_{j}^{\prime \prime} ; \theta_{0}=1, \theta_{j}=0 \\
& \eta=\infty: f_{0}^{\prime}=1, f_{j}^{\prime}=0 ; \theta_{i}=0 \quad i \geq 0, j>0
\end{aligned}
$$

\section{Results and Discussion}

The Equation (14) is that obtained by Bhattacharyya et al. [12] for the non-magnetic case and the remaining equations are ordinary linear differential equations and have been solved numerically by Newton's shooting method with fourth-order Runge-Kutta integration scheme for various values of the parameters. The velocity and temperature distributions for various values of parameters are shown in Figures 2-6 respectively.

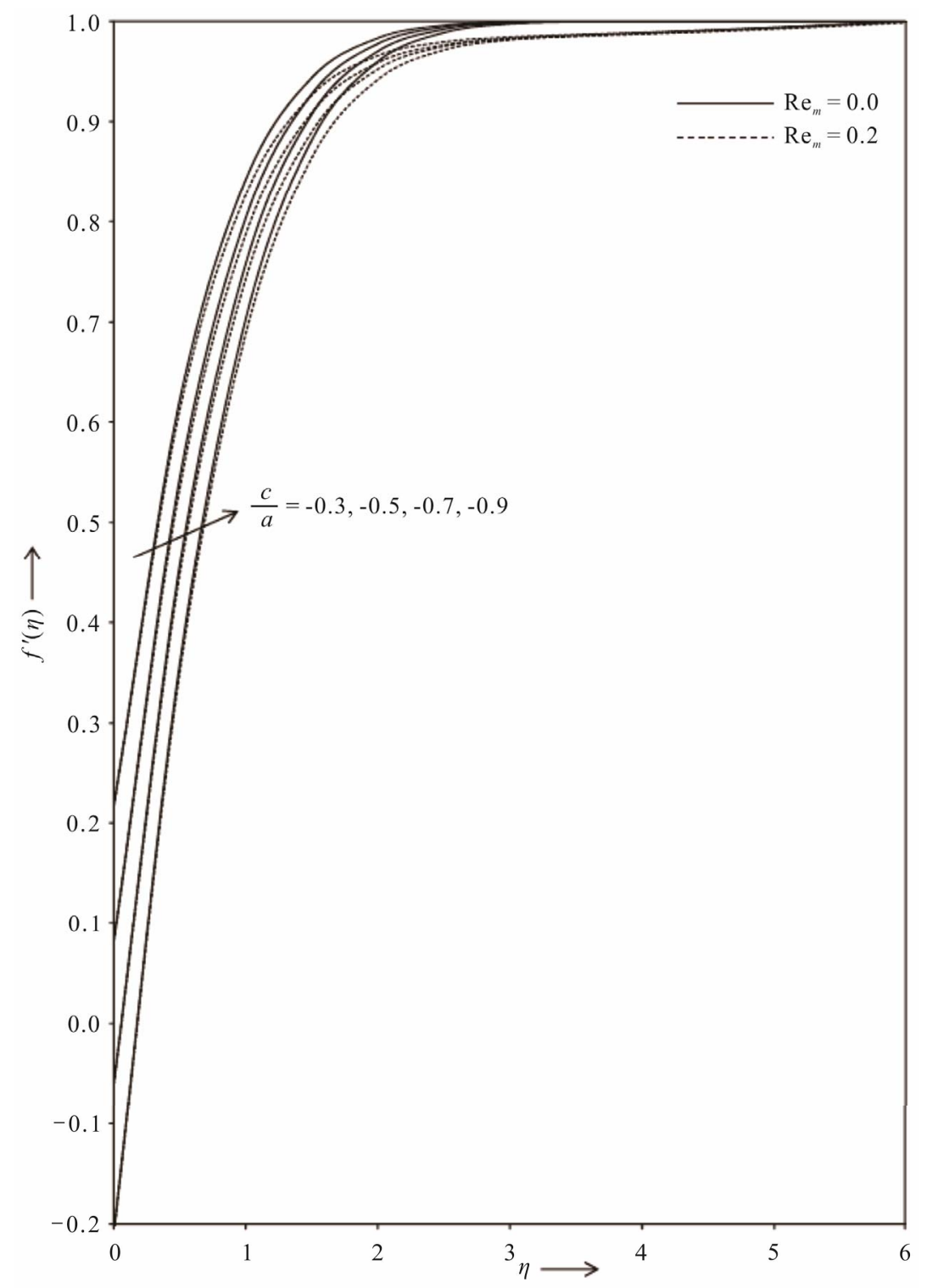

Figure 2. Velocity distribution against $\eta$ for various values of $\frac{c}{a}$ and $\operatorname{Re}_{m}$ with $\delta=0.5$. 


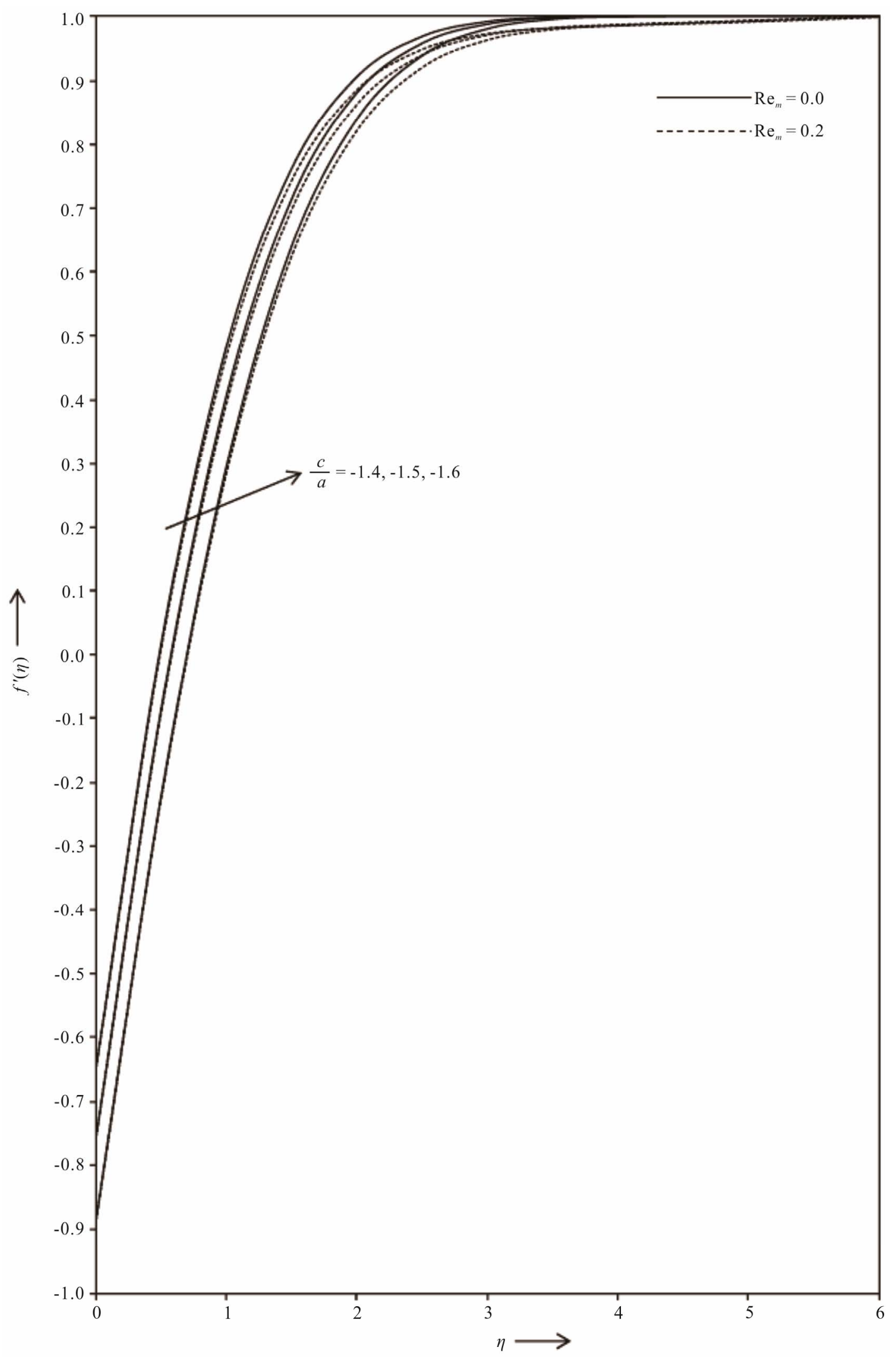

Figure 3. Velocity distribution against $\eta$ for various values of $\frac{c}{a}$ and $\operatorname{Re}_{m}$ with $\delta=0.5$. 


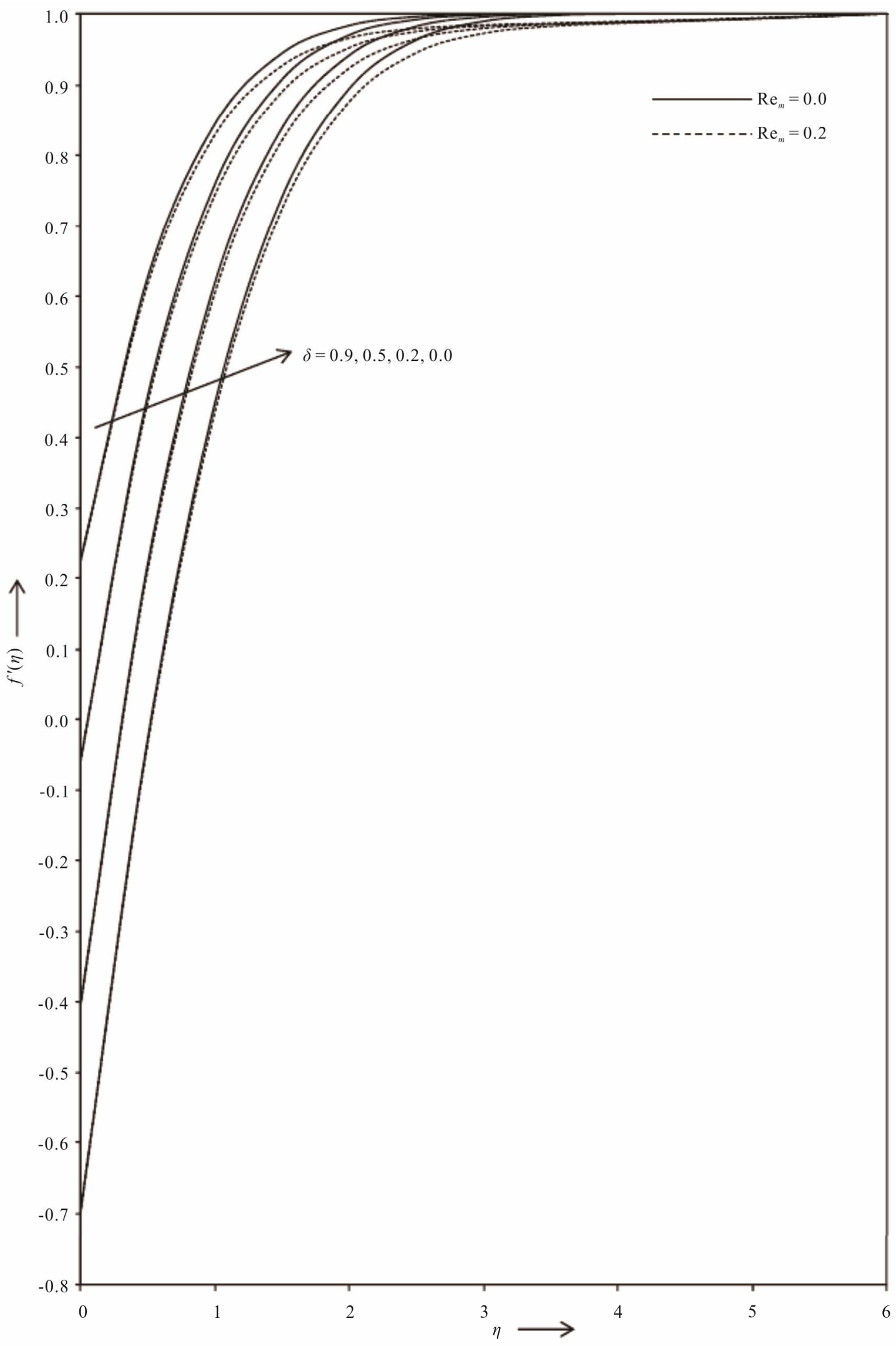

Figure 4. Velocity distribution against $\eta$ for various values of $\delta$ and $\operatorname{Re}_{m}$ with $\frac{c}{a}=-0.7$. 


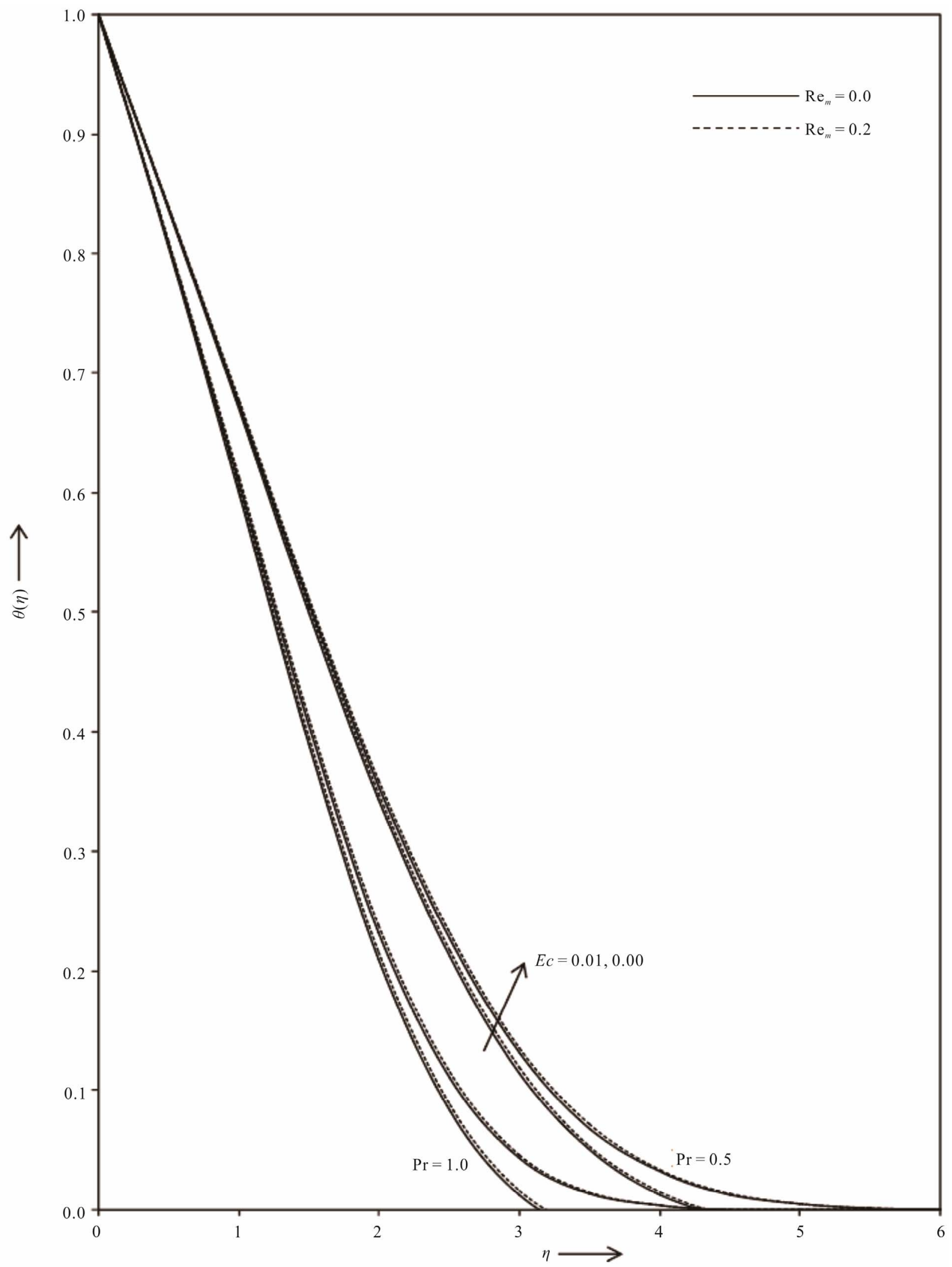

Figure 5. Temperature distribution against $\eta$ for various values of $\operatorname{Pr}, E c$ and $\operatorname{Re}_{m}$ with $\frac{c}{a}=-1.40$ and $\delta=0.5$. 


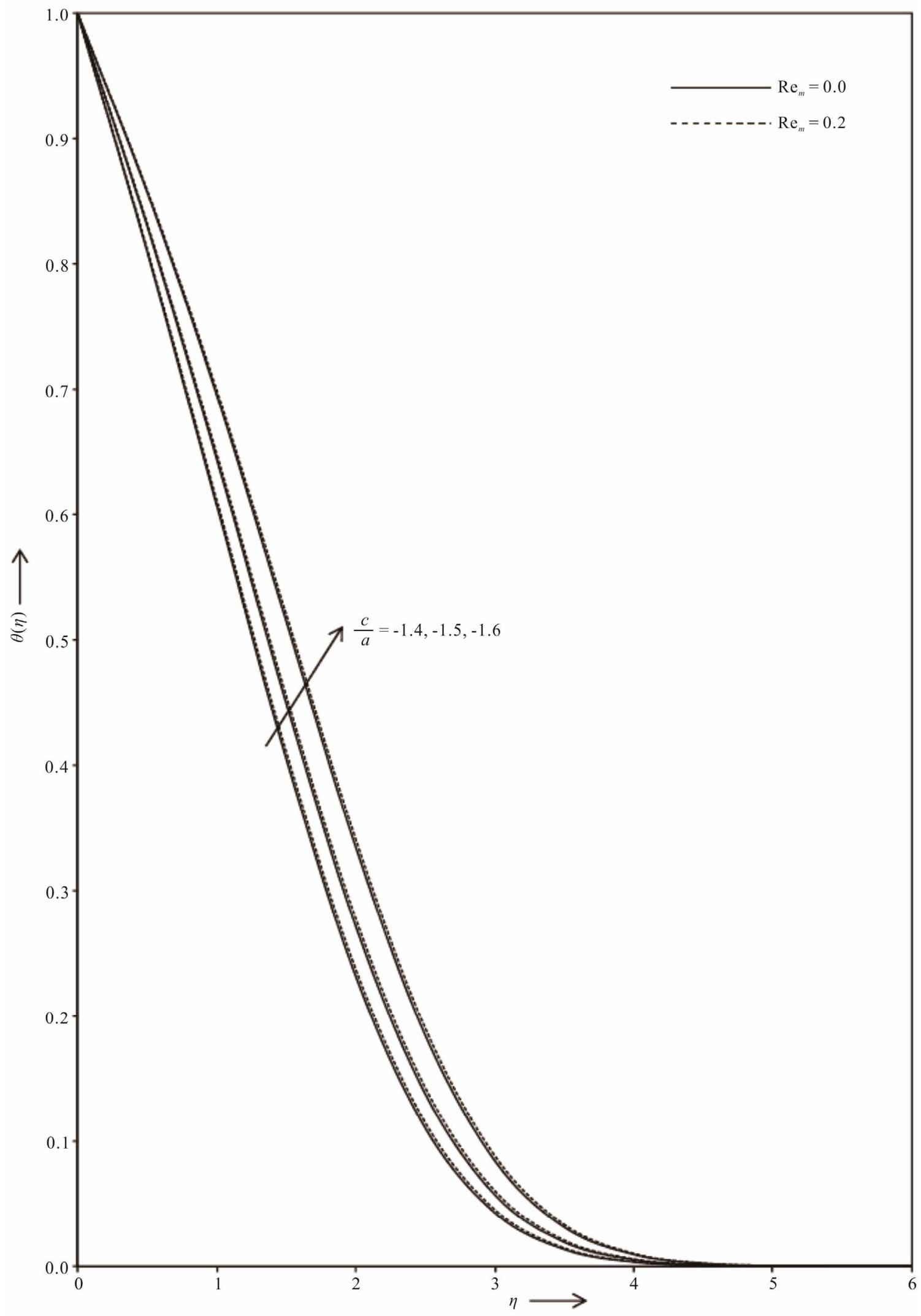

Figure 6. Temperature distribution against $\eta$ for various values of $\frac{c}{a}$ and $\operatorname{Re}_{m}$ with $\delta=0.5, \operatorname{Pr}=1$ and $E c=0.0$. 
The velocity profiles $f^{\prime}(\eta)$ for different values of the velocity ratio parameter $\frac{c}{a}$, the slip parameter $\delta$ and the magnetic parameter $\operatorname{Re}_{m}$ are shown in Figures 2-4. It is observed that the velocity boundary layer thickness increases with the increasing values of the velocity ratio parameter $\frac{c}{a}$ and the slip parameter $\delta$, whereas it decreases as the magnetic parameter $\operatorname{Re}_{m}$ increases for a fixed $\eta$.

The temperature profiles $\theta(\eta)$ for different values of the velocity ratio parameter $\frac{c}{a}$, the slip parameter $\delta$, the Prandtl number Pr, the Eckert number $E c$ and the magnetic parameter $\mathrm{Re}_{m}$ are plotted in Figures $\mathbf{5}$ and $\mathbf{6}$. It is observed that for the slip parameter $\delta=0.5$ the thermal boundary layer thickness decreases with the increasing values of the velocity ratio parameter $\frac{c}{a}$, the Prandtl number $\operatorname{Pr}$ and the Eckert number $E c$ and the reverse phenomenon is observed for the magnetic parameter $\operatorname{Re}_{m}$.

\section{Conclusions}

In this paper, the stagnation flow for two-dimensional electrically conducting fluid past a shrinking sheet with slip boundaries in the presence of a magnetic field is studied. The similarity equations are derived and solved numerically. It is found that the velocity boundary layer thickness increases with the increasing values of the velocity ratio parameter, the slip parameter. Further we observed that the magnetic parameter decreases with the increasing value of the velocity boundary layer thickness but the reverse phenomenon occurs for thermal boundary layer thickness. Also it observed that the thermal boundary layer thickness decreases with increasing values of the velocity ratio parameter, the Prandtl number and the Eckert number.

\section{REFERENCES}

[1] L. J. Crane, "Flow Past a Stretching Plate," Zeitschrift für angewandte Mathematik und Physik, Vol. 21, No. 4, 1970, pp. 645-647. $\underline{\text { doi:10.1007/BF01587695 }}$
[2] C. K. Chen and M. I. Char, "Heat Transfer of a Continuous, Stretching Surface with Suction or Blowing,” Journal of Mathematical Analysis and Applications, Vol. 135, No. 2, 1988, pp. 568-580.

[3] T. C. Chiam, "Stagnation-Point Flow towards a Stretching Plate,” Journal of the Physical Society of Japan, Vol. 63, No. 6, 1994, pp. 2443-2444. doi:10.1143/JPSJ.63.2443

[4] H. I. Andersson, "Slip Flow Past a Stretching Surface," Acta Mechanica, Vol. 158, No. 1-2, 2002, pp. 121-125. doi:10.1007/BF01463174

[5] P. D. Ariel, S. Hayat and S. Asghar, "The Flow of an Elastico-Viscous Fluid Past a Stretching Sheet with Partial Slip,” Acta Mechanica, Vol. 187, No. 1, 2006, pp. 2935. doi:10.1007/s00707-006-0370-3

[6] R. N. Jat and S. Chaudhary, "MHD Stagnation Flows with Slip,” Il Nuovo Cimento, Vol. 122B, No. 8, 2007, pp. 823-831.

[7] R. N. Jat and S. Chaudhary, "Magnetohydrodynamic Boundary Layer Flow near the Stagnation Point of a Stretching Sheet," Il Nuovo Cimento, Vol. 123B, No. 5, 2008, pp. 555-566.

[8] C. Y. Wang, "Stagnation Flow towards a Shrinking Sheet," International Journal of Non-Linear Mechanics, Vol. 43, No. 5, 2008, pp. 377-382.

doi:10.1016/j.ijnonlinmec.2007.12.021

[9] T. Fang, S. Yao, A. Zhang and A. Aziz, "Viscous Flow over a Shrinking Sheet with a Second Order Slip Flow Model," Communications in Nonlinear Science and Numerical Simulation, Vol. 15, No. 7, 2010, pp. 1831-1842. doi:10.1016/j.cnsns.2009.07.017

[10] S. Nadeem, A. Hussain and M. Khan, "HAM Solutions for Boundary Layer Flow in the Region of the Stagnation Point towards a Stretching Sheet," Communications in Nonlinear Science and Numerical Simulation, Vol. 15, No. 3, 2010, pp. 475-481. doi:10.1016/j.cnsns.2009.04.037

[11] K. Bhattacharyya and G. C. Layek, "Effects of Suction/ Blowing on Steady Boundary Layer Stagnation-Point Flow and Heat Transfer towards a Shrinking Sheet with Thermal Radiation,” International Journal of Heat and Mass Transfer, Vol. 54, No. 1-3, 2011, pp. 302-307. doi:10.1016/j.ijheatmasstransfer.2010.09.043

[12] K. Bhattacharyya, S. Mukhopadhyay and G. C. Layek, "Slip Effects on Boundary Layer Stagnation-Point Flow and Heat Transfer towards a Shrinking Sheet," International Journal of Heat and Mass Transfer, Vol. 54, No. 1, 2011, pp. 308-313.

doi:10.1016/j.ijheatmasstransfer.2010.09.041 